\title{
RANCANG BANGUN PROTOTYPE SMART OFFICE SYSTEM BERBASIS IOT PADA BUILDING AUTOMATION SYSTEM
}

\author{
Harun Sujadi ${ }^{1)}$, Nunu Nurdiana ${ }^{2)}$, Fahmi Nurbani ${ }^{3 \text { ) }}$ \\ Program Studi Informatika, Fakultas Teknik, Universitas Majalengka \\ Email: harunsujadi@gmail.com,nunu.nurdiana135@yahoo.com, nurbanifahmi@gmail.com
}

\begin{abstract}
The greatness of an Office located on the individuals that are fused braid synergy to achieve maximum results. Then it is reasonably mutually company trying to improve performance and productivity by providing the needs of employees in the internal work process, by providing representative offices to encourage employees to feel comfortable and motivated in order to provide the best achievements for the company, but to bring about a representative office there are a few problems that occur in office like its electrical energy continuously, lights and air conditioning always turned on, security is lacking because crimes like theft is still happening Enter the room, someone who is not an employee and still very rarely a firm which provides garden for rest. To realize the research prototype Smart Office System with the Arduino Mega 2560 and Raspberry Pi-based Internet of Things Project Builder Cayenne parts Building Automation System using the system development methodology waterfall and RUP (Rational Unified Process). In this prototype consists of a prototype with RFID sensors, DHT11, and LDR, prototype smart garden with soil moisture sensors and HC-SR04 for watering plants automatically and autonomous robot prototype line follower to monitor security outside the building. The existence of this system makes it easy to monitor in the office and representative offices materialize due to the presence of automation system that is applied in the office.
\end{abstract}

Keywords: Smart Office, Internet of Thing (IoT), Arduino, Raspberry Pi, Building Automation System.

\section{PENDAHULUAN}

Peradabanpun semakin maju, namun dibarengi dengan semakin terbatasnya sumber daya, kebutuhan dan gaya hidup yang semakin beragam, serta suasana kompetisi dalam berinteraksi, menuntut kita untuk memperkuat potensi dan daya saing dalam menjalani kehidupan berkualitas. Tak terkecuali, hal ini berdampak pada kondisi yang terjadi dalam dunia bisnis dan perusahaan. Dalam mendukung hal tersebut perlu dilakukan pemanfaatan kemajuan teknologi. Salah satu teknologi yang dapat dimanfaatkan adalah teknologi terbaru Internet of Things. Dalam penelitian Nasher dan Lestariningati (2016), Piyare mengatakan bahwa Internet of Things (IoT) dapat digambarkan sebagai penghubung benda sehari-hari seperti ponsel pintar, TV internet, sensor dan actuator ke internet dimana perangkat cerdas dihubungkan bersama memungkinkan bentuk-bentuk baru komunikasi. Teknologi IoT juga dapat diterapkan dalam membuat konsep baru dan ruang pengembangan yang luas yang diimplementasikan tidak hanya pada rumah untuk menyediakan kenyamanan, keamanan, dan meningkatkan kualitas hidup namun juga dapat diimplementasikan pada kantor atau perusahaan. Adanya teknologi IoT menjadikan implementasi dari kantor pintar atau lebih dikenal dengan istilah smart office dapat terwujud.

Kehebatan suatu instansi ataupun perusahaan terletak pada individu-individu yang saling berpadu menjalin sinergi untuk mencapai target dengan hasil maksimal. Maka sudah sewajarnya instansi ataupun perusahaan saling berusaha untuk meningkatkan performa dan produktivitasnya dengan mendukung dan menyediakan kebutuhan setiap individu dalam proses-proses kerja internal, diantaranya menyediakan ruang kerja atau kantor yang representative dengan kata lain tidak hanya 
sekedar layak, namun juga mampu mendorong setiap personil agar merasa nyaman dan termotivasi untuk memberikan prestasi terbaik mereka bagi perusahaan. Dalam Penelitian yang dilakukan oleh Pancorowati (2015), Sterk menemukan bahwa $83 \%$ pegawai sangat mengharapkan adanya pencahayaan yang tepat, area kerja yang sesuai, serta temperature udara yang nyaman. Harapan tersebut diikuti dengan ruang penyimpanan dokumen atau arsip yang nyaman, ruang kerja yang bersifat personal hingga pengaturan kabel dalam ruang kantor. Berikut ini adalah gambar yang menyimpulkan hal tersebut :

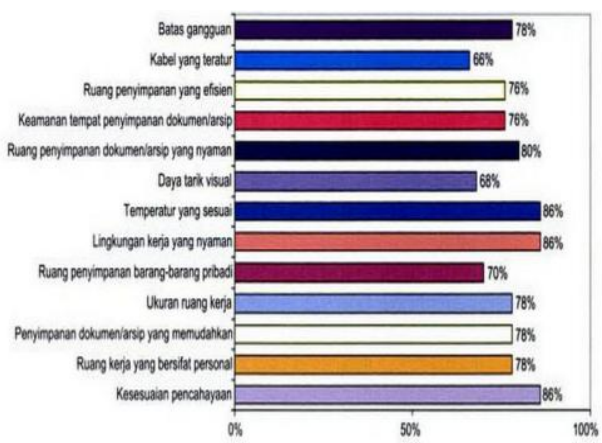

Gambar 1.1. Lingkungan kerja yang diharapkan (Pancorowati, 2015)

Banyak kantor atau perusahaan sudah menggunakan teknologi namun tidak melihat terhadap permasalahan yang sebenarnya terjadi, seperti penggunaaan energi listrik secara terus menerus tanpa memperhatikan berapa energi listrik yang digunakan perusahaan tersebut selama periode tertentu, seperti lampu kantor yang selalu menyala terus menerus, AC (Air Conditioner) yang menyala terus menerus sehingga kualitas udara didalam kantor kurang diperhatikan karena tidak adanya sistem yang mengatur mengenai kualitas udara didalam kantor, keamanan kantor atau perusahaan masih kurang baik sehingga masih banyak terjadinya kejahatan baik itu pencurian, ruangan dimasuki oleh seseorang yang bukan pegawai dan lingkungan luar office yang masih rentan dimasuki penyusup karena tidak adanya sistem yang memonitoring keamanan diluar office. Selain itu masih sangat jarang suatu perusahaan yang menyediakan taman untuk beristirahat para karyawan, taman yang adapun banyak yang tidak terawat, karena tidak adanya petugas khusus untuk merawat tanaman sehingga tanaman tidak disiram dan tidak mengetahui berapa banyak air yang dibutuhkan oleh tanaman. Sistem parkir juga memiliki kendala seperti kesulitan dalam mencari tempat parkir yang kosong dengan mengelilingi area parkir sehingga membutuhkan waktu yang lama.

Permasalahan tersebut bisa diatasi dengan membuat sistem kontrol otomatis dalam gedung atau disebut dengan building automation system yang dapat melakukan pengontrolan dan perawatan terhadap segala peralatan elektrikal dan mekanikal yang ada dalam suatu bangunan. Selain itu pengontrolan dan pemonitoran terhadap peralatan dapat dilakukan secara otomatis dan bersifat realtime. Hal ini akan menghemat tenaga kerja, peralatan elektronik akan berumur lebih panjang dan akan mengefektifkan penggunaan energi listrik. Selain itu perancangan building automation system ini akan diterapkan di prototype taman berupa smart garden dengan menggunakan soil moisture sehingga dalam penyiraman tanaman akan dilakukan secara otomatis berdasarkan dari kelembapan tanah yang dideteksi oleh sensor dan memanfaatkan sumber cahaya matahari yang diubah kedalam energi listrik untuk penerangan lampu taman serta building automation system diterapkan pada robot autonomous, dimana robot autonomous yang dibuat berupa robot Line Follower yang bergerak secara otomatis mengeliling lingkungan luar gedung untuk memonitoring keamanan luar gedung. Selain itu building automation system juga diterapkan didalam gedung (office) dengan menggunakan beberapa sensor seperti RFID (Radio Frequency Identification) untuk membuka pintu otomatis, sensor DHT11 untuk mengatur suhu ruangan dan sensor LDR (Light Dependent Resistor) untuk lampu ruangan otomatis berdasarkan intensitas cahaya yang dideteksi sensor. Dimana seluruh informasi automation system ini bisa dikontrol dengan media transmisi internet. 
Sehingga tujuan dari penelitian yang dilakukan ini yaitu membuat sebuah protype smart office system berbasis internet of things, mewujudkan gambaran kantor cerdas yang representative untuk meningkatkan produktifitas dan efektifitas karyawan.

\section{KAJIAN LITERATUR}

Terdapat beberapa penelitian yang relevan dengan penelitian ini diantaranya yaitu, Penelitian yang dilakukan oleh Prof. Dr. Khana Samrat Vivekanand Omprakash pada tahun 2011 melakukan penelitian dengan judul penelitian Wireless Home Security System with Mobile (Omprakash, 2011).

Penelitian yang dilakukan oleh Karol Furdik, Gabriel Lukac, Tomas Sabol, dan Peter Kostelnik pada tahun 2013 melakukan penelitian dengan judul penelitian The Network Architecture Design for an Adaptable IoT-based Smart Office Solution (Furdik, 2013).

Penelitian yang dilakukan oleh Muhammad Priyono Tri Sulistiyono, Danang Aditya Nugraha, Nurfatika Sari, Novita Karima, dan Wahid Asrori pada tahun 2015 melakukan penelitian dengan judul penelitian Implementasi IoT (Internet of Things) dalam pembelajaran di Universitas Kanjuruhan Malang (Sulistiyono, 2015).

Penelitian yang dilakukan oleh Renuka Bhuyar dan Saniya Ansari pada tahun 2016 melakukan penelitian dengan judul Smart Office Automation System (Bhuyar \& Ansari, 2016).

Penelitian yang dilakukan oleh Rohit Chasta, Rajesh Singh, Anita Gehlot, Raj Gaurav Mishra dan Sushabhan Choudhury pada tahun 2016 melakukan penelitian dengan judul penelitian A Smart Building Automation System (Chasta, 2016).

Setelah merujuk pada penelitian yang relevan, dalam penelitian ini akan menggunakan kontroler Arduino. Arduino adalah papan rangkaian elektronik (electronic board) open source yang mempunyai masukan dan keluaran serta terdapat komponen utama untuk pengendali program yang bisa ditulis dan dihapus dengan cara khusus yaitu sebuah chip mikrokontroler

Computer Science | Industrial Engineering | Mechanic Engineering | Civil Engineering berbasis ATMega328, ATMega 2560. Microcontroller itu sendiri adalah suatu chip atau IC (Integrated circuit) yang bisa diprogram menggunakan komputer. Program yang direkam bertujuan agar rangkaian elektronik dapat membaca input, memperoses dan menghasilkan output yang diinginkan. Hasilnya bisa berupa sinyal, tegangan, lampu, suara, getaran dan sebagainya (Saptaji, 2014).

\section{METODOLOGI PENELITIAN}

Metode yang digunakan dalam pengumpulan data adalah Metode Perpustakaan (Library Research). Dalam metode ini banyak mengutip dari beberapa bacaan yang berkaitan dengan

penelitian Smart Office System khususnya pada Building Automation System.

Secara lebih rinci pengumpulan data dalam penelitian ini diambil dari :

a. Bahan-bahan materi kuliah.

b. Laporan Penelitian yang berkaitan dengan penelitian smart office system mengenai building automation system.

c. Jurnal-jurnal yang terkait dengan penelitian smart office system mengenai building automation system.

d. Artikel-artikel ilmiah yang terkait dengan smart office system mengenai building automation system. 


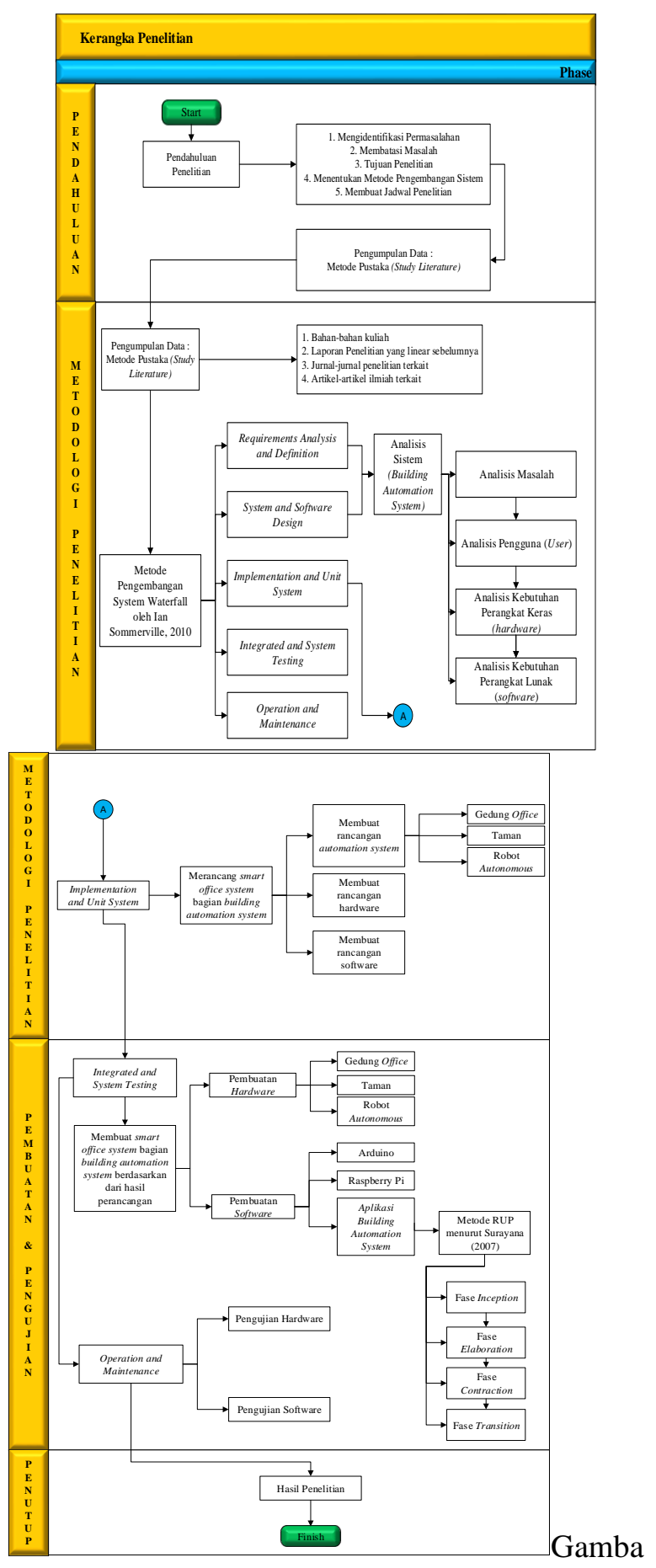

r 1.2. Kerangka Penelitian

\section{Metodologi Pengembangan Sistem}

Metode Waterfall ini memiliki beberapa tahapan menurut Sommerville (2010), yaitu sebagai berikut :

\section{a. Requirements Analysis and Definition}

Tahap yang pertama yaitu dengan mendefinisikan dan melakukan analisis terhadap sistem yang akan dirancang secara terperinci. Dimana pada tahap ini analisis yang dilakukan adalah analisis terhadap sistem secara keseluruhan, baik dari konsep prototype smart office yang akan dibangun, pembagian sub-sub sistem pada smart office, cara kerja sistem smart office, kendala yang muncul dalam melakukan perancangan smart office system, tujuan yang ingin dicapai dengan adanya smart office system serta fungsi dan spesifikasi smart office system khususnya pada Studi Kasus building automation system.

b. System and Software Design

Pada tahap system and software design ini merupakan tahap kedua kelanjutan dari tahap sebelumnya. Pada tahap ini menjelaskan secara lebih rinci mengenai analisis terhadap perangkat lunak (software) mulai dari analisis perancangan perangkat, spesifikasi pengguna (user), spesifikasi kebutuhan perangkat lunak, dan persyaratan lainnya. Karena dalam smart office system ini khususnya Studi Kasus building automation system akan dibuat perangkat lunak berupa aplikasi android untuk mengontrol dan memonitoring smart garden dan mengontrol robot autonomous juga menggunakan platform cayenne untuk konfigurasi sensor yang ada di gedung (office) agar bisa terkoneksi dengan internet. Selain analisis perangkat lunak, pada tahap ini juga menganalisis perangkat keras (hardware), mulai dari desain prototype, analaisis persyaratan perangkat keras, arsitektur sistem prototype, dan lain sebagainya.

c. Implementation and Unit System

Pada tahap ini merupakan tahap perancangan pada setiap sub-sub sistem berdasarkan dari hasil analisis pada tahap sebelumnya. Pada tahap ini dilakukan perancangan terhadap perangkat lunak (software), dan perancangan terhadap perangkat keras (hardware).

d. Integrated and System Testing

Tahap ini merupakan tahap kelanjutan dari tahap Implementation and Unit System, dalam tahap ini mulailah dibuatnya sistem perangkat lunak (software) yaitu aplikasi android untuk memonitoring smart garden dan mengontrol robot autonomous, serta dibangunnya 
perangkat keras (hardware) yaitu prototype smart office system berdasarkan dari hasil perancangan pada tahap sebelumnya. Setelah dilakukan pembuatan atau pembangunan software dan hardware maka akan dilakukan integrasi antara aplikasi yang dibuat (software) dan perangkat keras (hardware) sampai benar-benar terintegrasi.

e. Operation and Maintenance

Tahap yang terakhir yaitu tahap Operasi dan pemeliharaan. Pada tahap ini barulah smart office system bisa dijalankan secara keseluruhan dengan tetap berpedoman pada aturan pengoperasian. Selain itu, pada tahap ini juga dilakukan maintenance terhadap sistem guna untuk tetap mengoptimalkan kinerja pada sistem yang sudah berjalan.

Selain metode pengembangan sistem waterfall, juga menggunakan metode pengembangan sistem RUP (Rational Unified Process) khusus untuk pembuatan perangkat lunak aplikasi automation system berbasi android.

Metode ini memiliki beberapa tahapan menurut Suryana (2007), yaitu sebagai berikut :

\section{a. Inception}

Pada tahap ini dilakukan untuk mengidentifikasi sistem yang akan dikembangkan. Aktivitas yang dilakukan pada tahap ini antara lain penentuan arsitektur global target, identifikasi kebutuhan, perumusan persyaratan (fungsional, performansi, keamanan, GUI, dll.), perumusan kebutuhan pengujian (level unit, integrasi, sistem, performansi, fungsionalitas, keamanan, dll.), pemodelan diagram UML (diagram use case), dan pembuatan dokumentasi.

b. Elaboration

Pada tahap Elaboration merupakan kelanjutan dari tahap Inception. Pada tahap ini dilakukan perancangan desain secara lengkap berdasarkan dari hasil analisis inception. Aktivitas yang dilakukan pada tahap ini antara lain mencakup pembuatan desain arsitektur subsistem (architecture pattern), desain komponen sistem, desain format data (protokol komunikasi), desain antarmuka/tampilan, desain peta aliran tampilan, penentuan design pattern yang digunakan, pemodelan diagram UML (diagram sequence, class, activity, dll.).

c. Construction

Tahap ini merupakan tahap untuk melakukan pemodelan sistem yang akan dibuat dan membuat aplikasi sesuai desain yang telah dirancang pada tahap sebelumnya.

\section{d. Transition}

Pada tahap ini dilakukan penyempurnaan terhadap hal-hal yang masih memungkinkan untuk ditingkatkan kemampuannya. Pada tahap ini juga akan dicari dan ditentukan alat pendukung sehingga alat yang dibuat dapat bekerja lebih efisien dan efektif.

\section{HASIL DAN PEMBAHASAN}

Skema prototype smart office system seperti pada gambar dibawah ini :

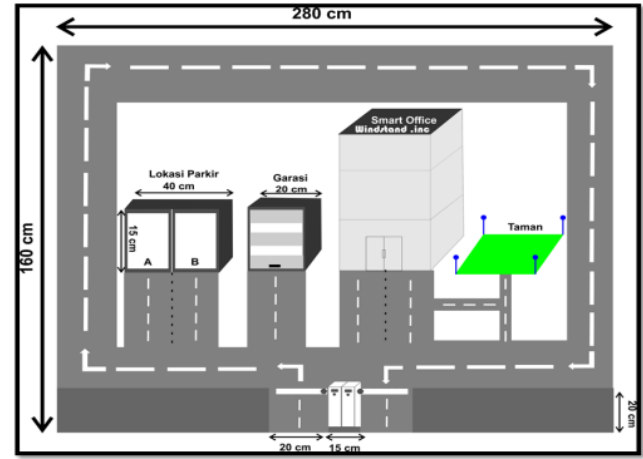

Gambar 1.3. Skema Prototype Smart Office System

Pada prototype smart office system khususnya pada building automation system, terdiri dari tiga bagian sub sistem yaitu automation system pada office, smart garden system dan robot autonomous. Cara kerja Building Automation System yaitu dapat melakukan pengontrolan dan perawatan terhadap segala peralatan elektrikal dan mekanikal yang ada dalam suatu bangunan. Selain itu pengontrolan dan pemonitoran terhadap peralatan dapat dilakukan secara otomatis dan bersifat realtime. Hal ini akan menghemat tenaga kerja, 
peralatan elektronik akan berumur lebih panjang dan akan mengefektifkan penggunaan energi listrik. Selain itu perancangan building automation system ini akan diterapkan di prototype taman berupa smart garden dengan menggunakan soil moisture sehingga dalam penyiraman tanaman akan dilakukan secara otomatis berdasarkan dari kelembapan tanah yang dideteksi oleh sensor dan memanfaatkan sumber cahaya matahari yang diubah kedalam energi listrik untuk penerangan lampu taman serta building automation system diterapkan pada robot autonomous, dimana robot autonomous yang dibuat berupa robot Line Follower yang bergerak secara otomatis mengeliling lingkungan luar gedung untuk memonitoring keamanan luar gedung.

Selain itu building automation system juga diterapkan didalam gedung (office) dengan menggunakan beberapa sensor seperti RFID (Radio Frequency Identification) untuk membuka pintu otomatis, sensor DHT11 untuk mengatur suhu ruangan dan sensor LDR (Light Dependent Resistor) untuk lampu ruangan otomatis berdasarkan intensitas cahaya yang dideteksi sensor. Dimana seluruh informasi automation system ini bisa dikontrol dengan media transmisi internet.

\section{Analisis Kebutuhan Perangkat Lunak (Software)}

Perangkat lunak yang dibutuhkan dalam prototype smart office system pada Studi Kasus building automation system yaitu sebagai berikut
a. Arduino IDE 1.6.5
b. Android
c. FritzingMIT App Inventor
d. Cayenne

\section{Analisis Kebutuhan Perangkat Keras (Hardware)}

a. Arduino Mega 2560Arduino Mega 2560 ini digunakan pada office dengan memanfaatkan ATMega 2560 karena kapasitas penyimpanan yang lebih besar. Arduino mega ini digunakan untuk mengontrol sensor-sensor yang ada didalam office seperti sensor RFID, sensor cahaya (LDR), sensor suhu (DHT11), mengatur lampu, dan lain-lain.

b. Raspberry Pi

Raspberry $\mathrm{Pi}$ akan digunakan pada robot autonomous. Raspberry $\mathrm{Pi}$ ini akan diintegrasikan dengan Arduino Uno R3. Arduino Uno berfungsi untuk mengontrol robot line follower-nya.

Selain itu juga terdapat beberapa komponen hardware tambahan diantaranya, Ethernet Shield W5100, Sensor Soil Moisture, Sensor IR, Sensor RFID, Sensor Cahaya (LDR), Sensor DHT11, motor servo, HC-SR04, modul bluetooth HC-05, buzzer, LED, LCD, breadboard, kabel jumper, dan lain-lain.

\section{Perancanagan Hardware Smart Office System}

Dalam perancnagn hardware pada smart office system terdiri dari 3 (tiga) perancangan yaitu sebagai berikut :

a. Perancangan Automation System pada Office

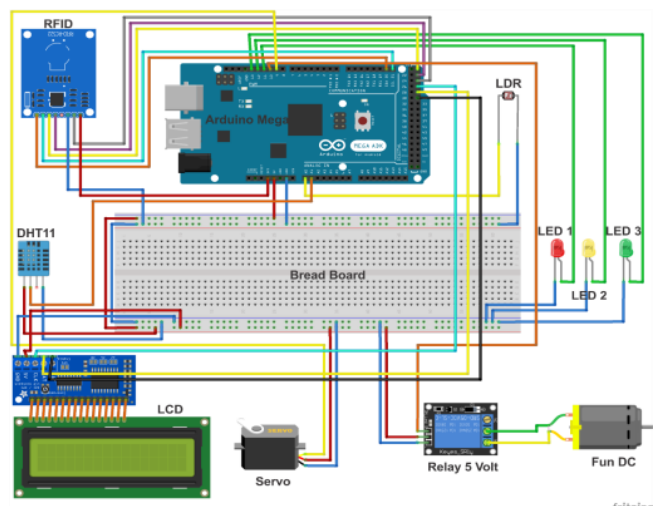

Gambar 1.4. Perancangan Rangkaian Hardware pada Office

Tabel 1.1. Pin I/O Automation System pada Arduino yang Digunakan

\begin{tabular}{|c|l|l|}
\hline $\begin{array}{c}\text { N } \\
\mathbf{0}\end{array}$ & $\begin{array}{l}\text { Nama } \\
\text { Perangaka } \\
\text { t Keras }\end{array}$ & \multicolumn{1}{|c|}{ Pin pada Arduino } \\
\hline 1 & $\begin{array}{l}\text { Sensor } \\
\text { RFID }\end{array}$ & $\begin{array}{l}\text { SDA, SCK, MOSI, } \\
\text { MISO, GND, 3,3 } \\
\text { Volt, Digital 21 }\end{array}$ \\
\hline 2 & $\begin{array}{l}\text { Sensor } \\
\text { LDR }\end{array}$ & GND dan Analog 0 \\
\hline 3 & $\begin{array}{l}\text { Sensor } \\
\text { DHT11 }\end{array}$ & GND, VCC, Analog 1 \\
\hline 4 & LCD & GND, VCC, Digital \\
\hline
\end{tabular}




\begin{tabular}{|l|l|l|}
\hline & & $\begin{array}{l}27, \text { Digital 29, Digital } \\
31\end{array}$ \\
\hline 5 & $\begin{array}{l}\text { Relay 5 } \\
\text { Volt }\end{array}$ & $\begin{array}{l}\text { GND, VCC, Digital } \\
10\end{array}$ \\
\hline 6 & Fun DC & $\begin{array}{l}\text { IN 1, IN 2 (Relay 5 } \\
\text { volt) }\end{array}$ \\
\hline 7 & Servo & GND, VCC, Digital 9 \\
\hline 8 & LED 1 & GND dan Digital 13 \\
\hline 9 & LED 2 & GND dan Digital 12 \\
\hline 10 & LED 3 & GND dan Digital 11 \\
\hline
\end{tabular}

b. Perancangan Smart Garden System

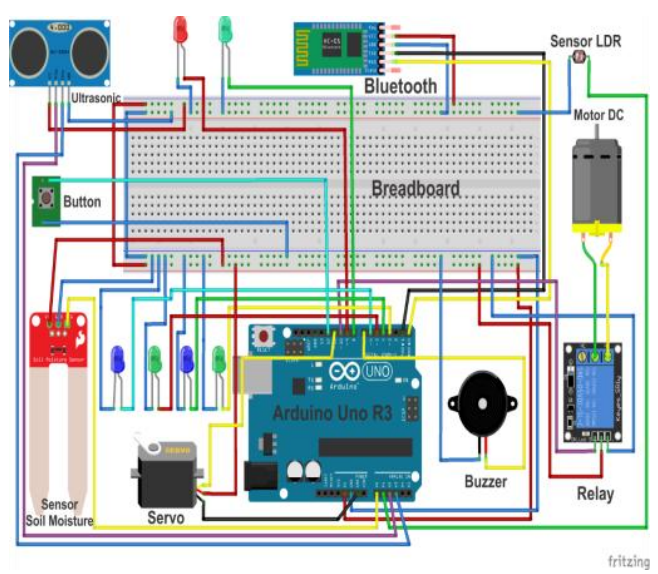

Gambar 1.5. Perancangan Rangkaian Smart Garden

Tabel 1.2. Pin I/O Smart Garden pada Arduino yang Digunakan

c. Perancangan Robot Autonomous

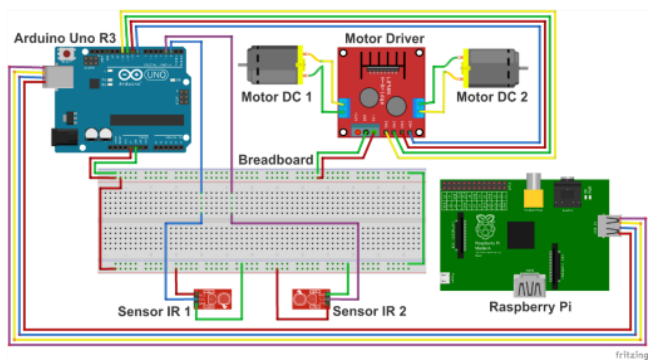

Gambar 1.6. Perancangan Rangkaian Robot Autonomous

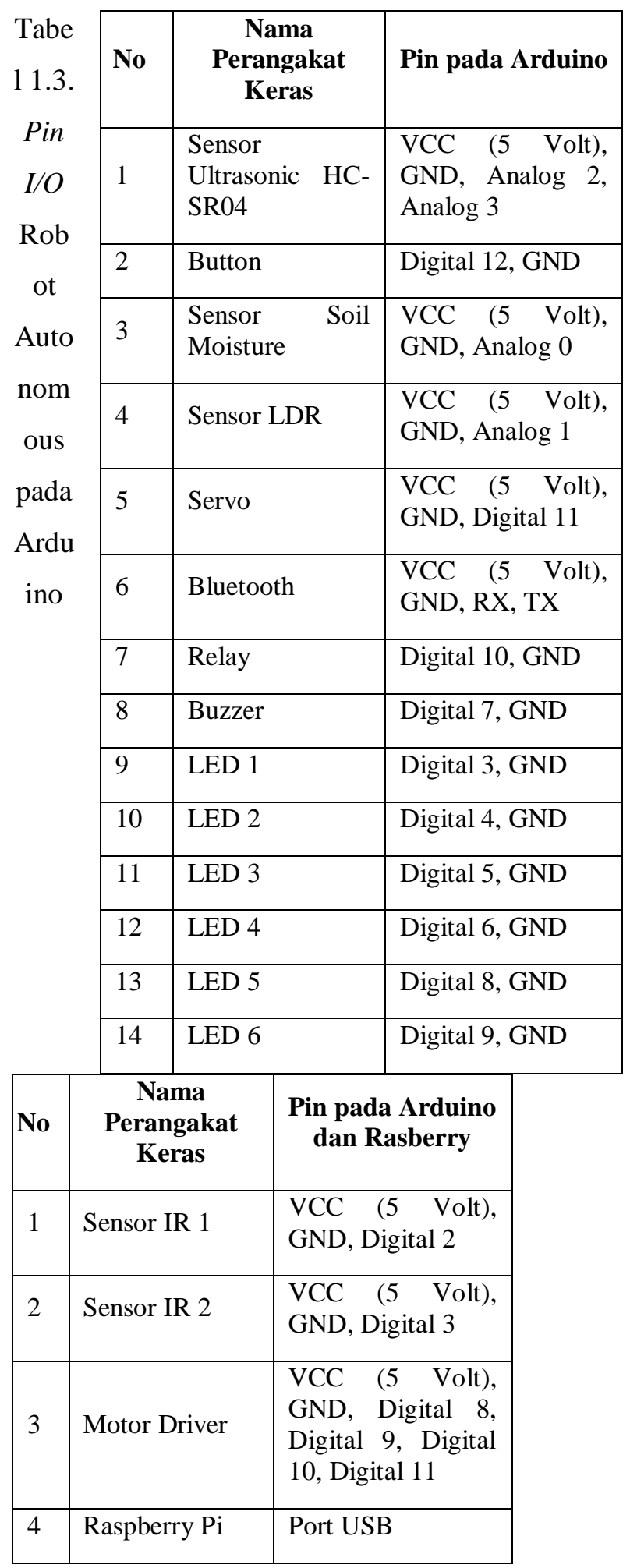

Hasil Pembuatan Prototype Smart Office System 


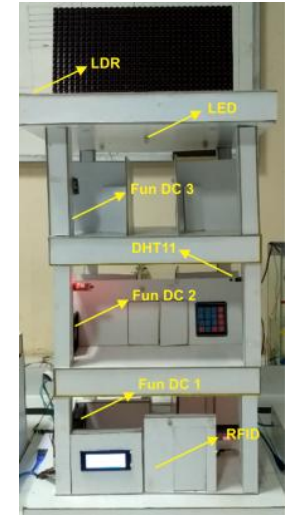

Gambar 1.7. Building automation system pada office

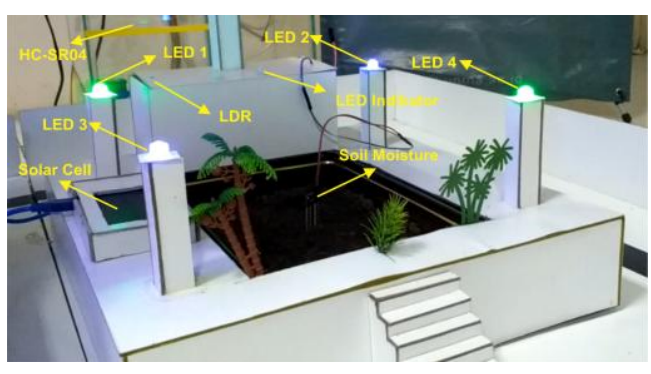

Gambar 1.8. Smart Garden

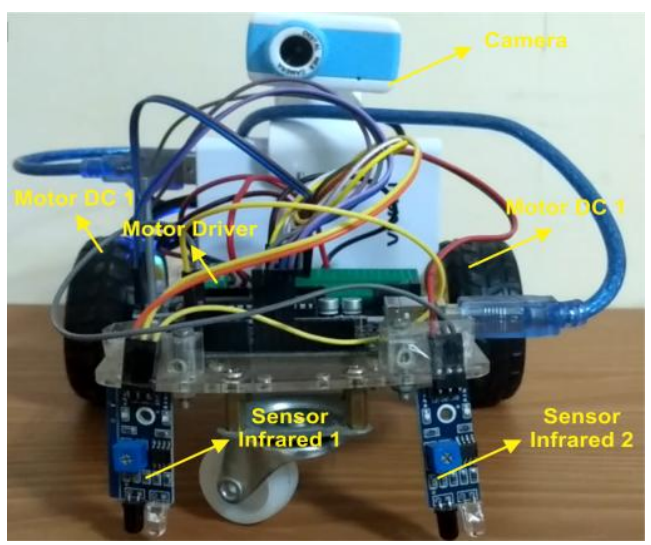

Gambar 1.9. Robot Line Follower

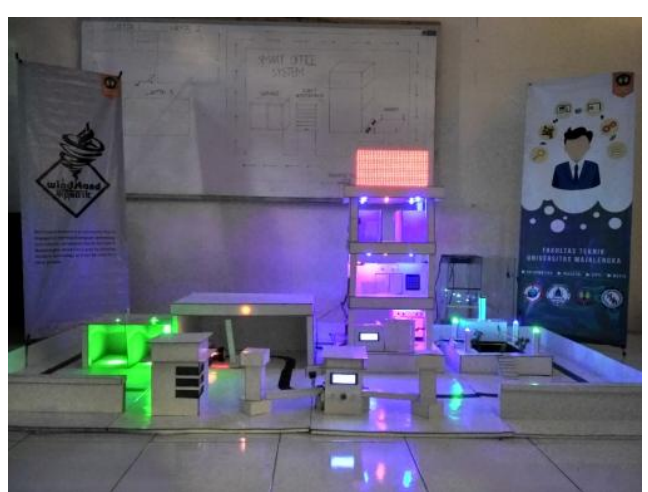

Computer Science | Industrial Engineering | Mechanic Engineering | Civil Engineering 270
Gambar 1.10. Smart Office System

\section{Kesimpulan}

Berdasarkan hasil pembahasan dan pengujian yang sudah dilakukan, maka kesimpulan dari penelitian ini adalah :

a. Smart office system khususnya building automation system ini terdiri dari automation system pada office, smart garden system, dan robot autonomous line follower dengan Arduino menggunakan bahasa pemrograman $\mathrm{C}$, kemudian diintegrasikan dengan Raspberry Pi dan media transmisi data internet untuk bisa dikontrol melalui platform cayenne dengan melalukan perancangan hardware dan software menggunakan metode pengembangan sistem Waterfall dan Rational Unified Process (RUP). Smart Office System juga mewujudkan kantor representatif sehingga meningkatkan kualitas dan efektifitas karyawan dalam bekerja.

b. Raspberry dan Arduino diintegrasikan dengan menggunakan media transmisi melalui kabel USB 2.0. Sistem dihubungkan dengan media transmisi data internet untuk terintegrasi dengan cayenne sehingga peralatan elektrikal akan mudah untuk dikontrol dan dimonitoring lewat internet dan memudahkan dalam perawatan peralatan elektrikal.

c. Robot Autonomous yang dirancang yaitu robot autonomous line follower menggunakan Raspberry Pi sebagai sistem pengontrol keamanan dan Arduino Uno R3 dengan Bahasa pemrograman $\mathrm{C}$ yang diintegrasikan dengan sensor sensor infrared (IR) yang berjumlah 2 (dua) yang berfungsi untuk mendeteksi garis warna hitam dan putih, input yang diterima oleh sensor IR akan dikirim ke Arduino untuk diproses dan mengirimkan output ke motor driver untuk menggerakan motor DC sehingga robot line follower akan bergerak secara otomatis dengan mengikuti garis berwarna hitam untuk melakukan monitoring keamanan terhadap lingkungan kantor. 
d. Smart garden diprogram dengan menggunakan Bahasa pemrograman $\mathrm{C}$ dengan memanfaatkan sensor soil moisture untuk mendeteksi kelembapan tanah yang dikirim melalui Arduino Uno R3. Jika sensor soil moisture mendeteksi kelembapan kurang dari $50 \%$ maka tanah kekurangan air yang kemudian akan diproses oleh sistem dan sistem akan mendeteksi ketersediaan air pada tempat penampungan air dengan menggunakan sensor ultrasonic dengan tipe HC-SR04. Apabila ketinggian air dalam penampungan lebih dari $5 \mathrm{~cm}$ maka Arduino akan membuka channel 1 (satu) pada relay, sehingga relay mendapatkan arus listrik untuk mengalirkan air dan menyiram tanaman sampai sensor soil moisture mendeteksi kadar air dalam tanah harus melebihi $50 \%$.

\section{REFERENSI}

Bhuyar, R., \& Ansari, S. (2016). Smart Office Automation System. International Journal of Emerging Trends \& Technology in Computer Science.

Chasta, R., Singh, R., Gehlot, A., Mishra, R. G., \& Choudhury, S. (2016). A Smart Building Automation System. International Journal of Smart Home.

Furdik, K., Lukac, G., Sabol, T., \& Kostelnik, d. P. (2013). The Network Architecture Design for an Adaptable IoT-based Smart Office Solution. International Journal of Computer Networks and Communications Security.

Omprakash, K. S. (2011). Wireless Home Security System With Mobile. International Journal of Advanced Engineering Technology.

Pancorowati, M. H. (2015). Pengaruh Tata Ruang Kantor Terhadap Produktivitas Kerja Karyawan. Ejournal UNESA.

Saptaji. (2014). 5 menit handling rtc ds3231 ds3232 dengan Arduino. Retrieved February 17, 2017, from http://saptaji.com/2015/07/19/5-menithandling-rtcds3231ds3232denganarduino/
Sommerville, I. (2010). Software Engineering (ninth ed.). Massachussets: Addision Wesley.

Sulistiyono, M. P., Nugraha, D. A., Sari, N., Karima, N., \& Asrori, W. (2015). Implementasi IoT (Internet of Things) dalam pembelajaran di Universitas Kanjuruhan Malang. Semartics Journal.

Sujadi, Harun, Tri Ferga Prasetyo, And Pafsi Paisal. "Pengembangan Sistem Monitoring Keamanan Sepeda Motor Berbasis Internet Of Things." $J$ Ensitec 5.01 (2018). 